\title{
Rainfall and temperature scenarios for Bangladesh for the middle of 21st century using RegCM
}

\author{
Md Mizanur Rahman ${ }^{1, *}$, Md Nazrul Islam ${ }^{2}$, Ahsan Uddin Ahmed ${ }^{3}$ and F Georgi ${ }^{4}$ \\ ${ }^{1}$ SAARC Meteorological Research Centre, Dhaka, Bangladesh. \\ ${ }^{2}$ Center of Excellence for Climate Change Research (CECCR), Department of Meteorology, \\ King Abdulaziz University, Jeddah, Saudi Arabia. \\ ${ }^{3}$ Centre for Global Change, Dhaka, Bangladesh. \\ ${ }^{4}$ Earth System Physics Section, Abdus Salam International Center for Theoretical Physics, Trieste, Italy. \\ ${ }^{*}$ Corresponding author. e-mail: mrahman426@yahoo.com
}

Regional Climate Model of version 3 (RegCM3) was driven with Emissions Scenarios A2 of ECHAM4 at $0.54^{\circ} \times 0.54^{\circ}$ horizontal grid resolution in two parameterizations: Grell scheme with Arakawa-Schubert (GAS) and Fritch-Chappell (GFC) assumptions. The simulated rainfall and mean surface air temperature were calibrated and validated against ground-based observed data in Bangladesh during the period 1961-1990. The Climate Research Unit (CRU) data is also used for understanding the model performance. Better performance of RegCM3 obtained through validation process, made it confident in utilizing it in rainfall and temperature projection for Bangladesh in the middle of 21st century. Rainfall and mean surface air temperature projection for Bangladesh is experimentally obtained for 2050 and 2060. This work discloses that simulated rainfall and temperature are not directly useful in application-oriented tasks. However, after calibration and validation, reasonable performance can be obtained in estimating seasonal and annual rainfall, and mean surface air temperature in Bangladesh. The projected change of rainfall for Bangladesh is about $+35 \%$ for monsoon season (JJAS), $-67 \%$ for pre-monsoon (MAM), $-12 \%$ for post-monsoon (ON) and $107 \%$ for winter (DJF) for 2050 . On an average, rainfall may be less by more than $50 \%$ for all seasons for the year 2060. Similarly, change of mean surface air temperature in different months is projected about $0.5^{\circ}-2.1^{\circ} \mathrm{C}$ and $0.9^{\circ}-3.5^{\circ} \mathrm{C}$ for the year 2050 and 2060 , respectively.

\section{Introduction}

Being a disaster-prone country, Bangladesh almost every year, experiences disasters such as tropical cyclones, storm surges, coastal erosion, floods, and droughts causing heavy loss of lives and property and jeopardizing developmental activities. These natural calamities add an extra burden to the country which is already fraught with many problems such as high population density, shortage of land to accommodate the people, food security, human health, illiteracy, and so on. Bangladesh is likely to be one of the most vulnerable countries of the world affected by the effect of climate change (Ali 1999). The global warming due to the increase in greenhouse gas concentrations in the earth's atmosphere and the consequent sea level rise (SLR) are going to add fuel to the fire. Almost every sector of the socio-economic lives in Bangladesh is likely to be affected by climate change. Most of the climate change impacts in Bangladesh are likely to come from the south, i.e., from the Bay of Bengal and the adjoining north Indian Ocean (Ali 1999). These waters are the sources of tropical cyclones and storm surges, coastal erosion, monsoon wind, evaporation for monsoon rainfall, floods, and droughts.

Keywords. Rainfall; temperature; projection; climate change; simulation; Bangladesh. 
Bangladesh is highly vulnerable as it is low-lying, located on the Bay of Bengal in the delta of the Ganges, Brahmaputra and Meghna and densely populated. Its economy strongly depends on agriculture and natural resources that are sensitive to climate change and SLR. The impact of higher temperatures, more extreme weather events such as floods, cyclone, severe drought, and SLR are already being felt in South Asia and will continue to intensify (Haq et al 1998; Karim et al 1998). In this connection proper planning for the management of water resources are important for the country. Long term planning is not possible without an idea of climate change in future. Climate models are the main tools available for developing projections of climate change in the future (Houghton et al 1995, 2001). In recent years, high horizontal resolution MRI-Atmospheric General Circulation Models (AGCM) experiments are conducted using the time-slice method (Bengtsson et al 1996; IPCC 2001), which is a two-tier global warming projection using an atmosphere-ocean general circulation model (AOGCM) and an AGCM with horizontal resolution higher than that of the atmospheric part of the AOGCM. These predictions may be adequate for the area where terrain is reasonably flat, uniform and away from coasts. However, regional climate model is the best tool for dynamical downscaling of climate features for obtaining detailed information for a particular region (Giorgi et al 2001; Jones et al 2004). Dynamical downscaling from regional climate model outputs is important in understanding the local phenomena at a particular place for every country.

Human-induced changes in the global climate and associated SLR are widely accepted phenomena among policy makers and scientists. The Intergovernmental Panel on Climate Change (IPCC) concluded that "the balance of evidence suggests a discernible human influence on global climate" (IPCC 1996). The exact magnitude of the changes in the global climate is still uncertain and is a subject of worldwide scientific studies. This paper examines the calibration and validation of rainfall and temperature in Bangladesh derived from a Regional Climate Model (RegCM) for the baseline period 1961-1990. Finally, projections are made for rainfall and temperature in Bangladesh for 2050 and 2060.

\section{Model description and methodology}

\subsection{Model description}

The Regional Climate Model (RegCM3) system originally developed at the National Center for
Atmospheric Research (NCAR), is maintained in the Earth System Physics (ESP) section of the ICTP, Italy. RegCM idea was originally proposed by Dickinson et al (1989) and Giorgi (1990). This idea was based on the concept of one-way nesting in which large scale meteorological fields from General Circulation Model (GCM) provides initial and time-dependent meteorological lateral boundary conditions (LBCs) for high resolution Regional Climate Model (RCM) simulations, with no feedback from the RCM to the driving GCM. RegCM3 is based on hydrostatic primitive equation and grid point containing 16 vertical layers. RegCM3 is made freely available for scientists of developing countries to generate climate change scenarios in the future.

\subsection{Methodology}

RegCM3 was run at $0.54^{\circ} \times 0.54^{\circ}$ horizontal grid resolution in a large domain that covers $65^{\circ}-117^{\circ} \mathrm{E}$ and $5^{\circ}-38^{\circ} \mathrm{N}$ for the baseline period $1961-1990$ to calibrate model outputs with observed data. Grell scheme with Arakawa-Schubert (GAS) and FritchChappell (GFC) assumptions were used as convective precipitation options in model simulation. The

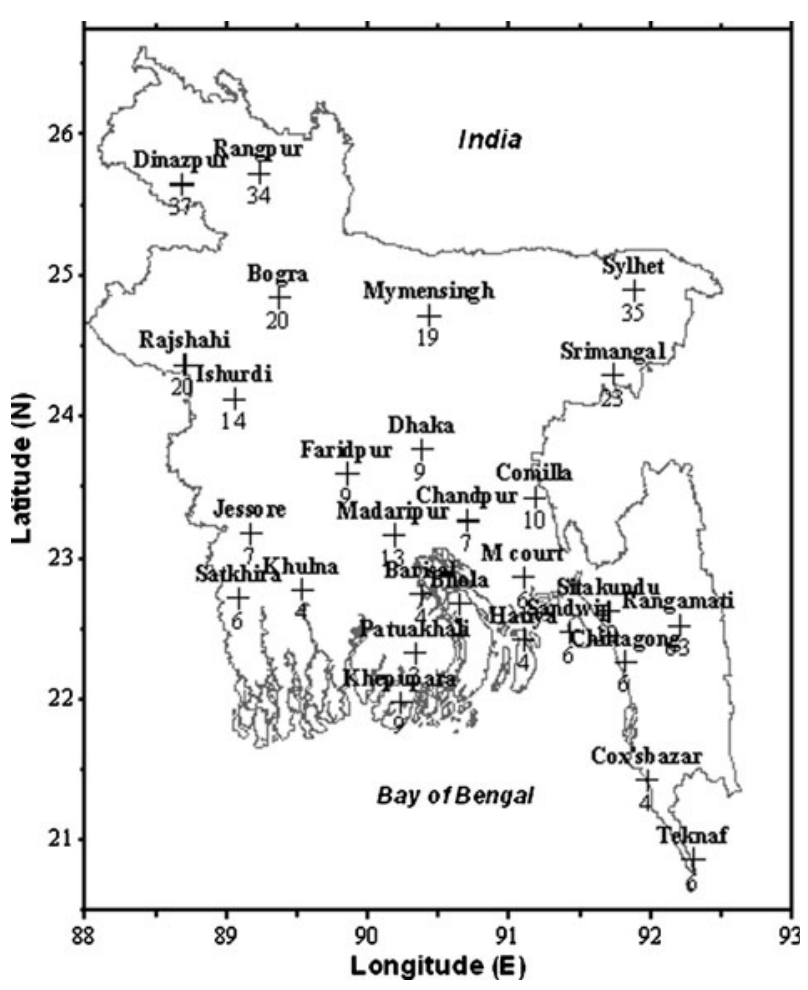

Figure 1. Plus marks represent Bangladesh Meteorological Department (BMD) observation stations. Above plus mark the name of stations and below plus mark the elevation (meters) are shown. 
Grell parameterization is implemented using two closure assumptions:

1) the Arakawa and Schubert closure (Grell et al 1994) and

2) the Fritsch and Chappell closure (Fritsch and Chappell 1980).

The GFC assumptions were found suitable for rainfall over Bangladesh than other assumptions (Rahman et al 2007). Calibration and validation of RegCM3 are considered for Bangladesh to understand the model performance in simulating climatic parameters such as rainfall and temperature. Surface rainfall data of Bangladesh collected from the Bangladesh Meteorological Department (BMD) observations network is shown in figure 1 . These observations were used for the calibration of model generated rainfall and temperature. While making a grid point over the domain at $0.54^{\circ} \times 0.54^{\circ}$ resolution, a number of grids are found which do not contain any observation station or site in that grid. For the application purpose of RegCM3, it is very important for Bangladesh to find out the appropriate calibration procedure. So, an analysis was performed on a point-to-point basis (Islam et al 2008). In this procedure, observed data at a particular station/site is considered as the representative of that location. Grid value of the model data is compared with the observed data. If more than one observation stations or sites exist within a grid, then average value of all the observational sites is considered as the representative value for that grid. Daily rainfall data collected from BMD are processed to obtain monthly, seasonal, annual and long term values. Simulated rainfall and temperature are extracted for 28 observational stations/sites of BMD and then they are converted to monthly, seasonal, annual and long term values. The average over 28 stations is considered as the country average. Estimated rainfall and temperature were obtained from model generated future scenarios with the help of equation (1) (refer section 4).

The Special Report on Emissions Scenarios (SRES) A2 of ECHAM4 was used to drive the RegCM3 for 2050 and 2060. Daily CRU (Climate Research Unit) data were used to understand the spatial distribution of model generated rainfall and temperature. The simulated rainfall and temperature during the period 1961-1990 were taken as the normal or base line. In addition, NCEP/ NCAR reanalysis dataset at 6-hourly intervals were used for the initial and boundary conditions and global sea surface temperature one-degree monthly gridded data from the Hadley Centre Met Office were used to make the simulations for the period 1961-1990.

\section{Results}

\subsection{Simulation (GFC) of rainfall over Bangladesh}

The high resolution model simulations generated rainfall over Bangladesh using RegCM3 have been studied in detail to evaluate the model skills during the period 1961-1990.

\subsection{Monthly rainfall}

The mean annual cycles of the Bangladesh monthly rainfall obtained from the simulation (GFC) and observation are shown in figure 2. The modelgenerated annual cycles of rainfall match reasonably well with the observed data. However, there appears to be a significant positive bias in the rainfall during the onset phase of the monsoon. The model produces excess rainfall during the transitional months of May and June.

The model overestimates rainfall for the dry month of November to the onset phase of monsoon, i.e., the month of June. During July to October, the model estimates almost the same as the observed rainfall. In fact, the characteristics of precipitation systems, especially the vertical height and precipitation strength in this region are different in different rainy periods, whereas the use of same cloud parameterization cannot represent variable atmospheric conditions in different periods (Islam and Uyeda 2008).

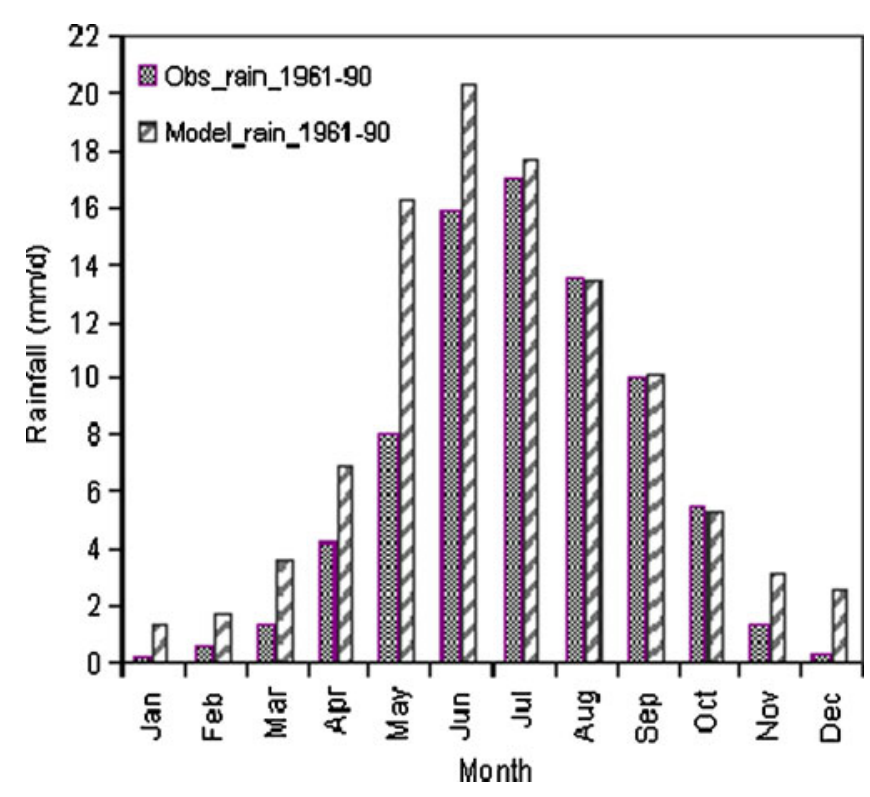

Figure 2. Comparison of simulated (GFC) monthly rainfall $(\mathrm{mm} / \mathrm{d})$ with the observed data in Bangladesh during the period 1961-1990. 


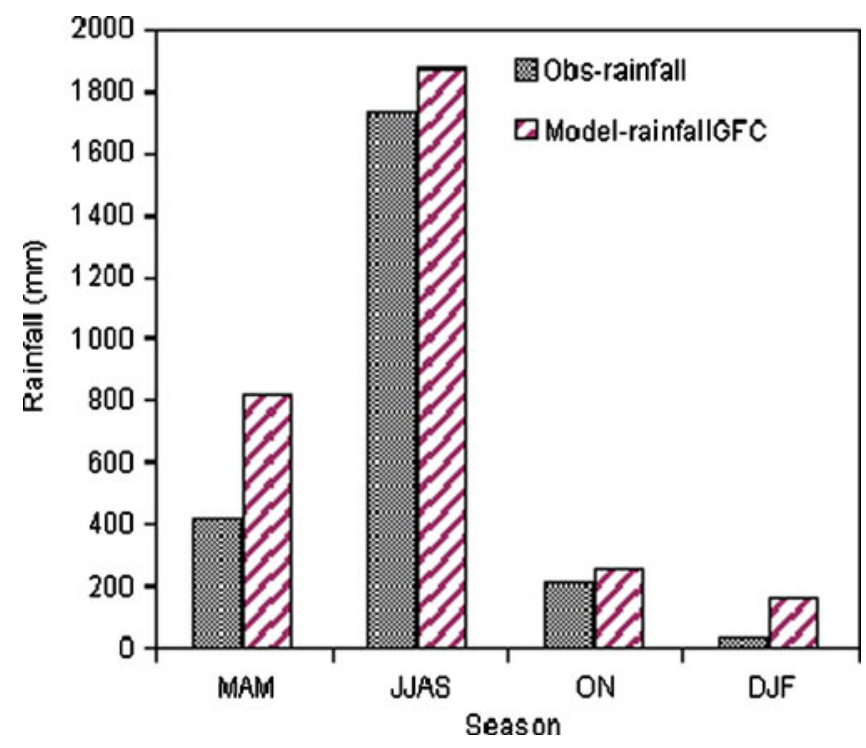

Figure 3. Comparison of simulated (GFC) seasonal rainfall $(\mathrm{mm} / \mathrm{d})$ with the observed data in Bangladesh during the period 1961-1990.

\subsubsection{Seasonal rainfall}

It is seen that the model has overestimated rainfall in winter (DJF), pre-monsoon (MAM) and monsoon (JJAS) seasons. During the post-monsoon $(\mathrm{ON})$ season, model simulated (GFC) values are almost the same as the observed values (figure 3 ).

The average monsoon rainfall (JJAS) for the baseline (1961-1990) simulated (GFC) by RegCM3 is $1877 \mathrm{~mm}$ with a standard deviation of $222 \mathrm{~mm}$ (table 1) whereas All-Bangladesh Summer Monsoon Rainfall (ABSMR) based on 28 stations averaged during the period of 1961-1990 is $1729 \mathrm{~mm}$ with a standard deviation of $228 \mathrm{~mm}$. The model seems to have overestimated the ABSMR; its variability is almost the same as the observed values. During the winter, pre-monsoon and post-monsoon period model simulated rainfall is 166, 822 and $259 \mathrm{~mm}$ with standard deviation of 115, 218 and
$126 \mathrm{~mm}$, respectively. Similarly, observed rainfall is 33,418 and $211 \mathrm{~mm}$ with a standard deviation of 20, 148 and $126 \mathrm{~mm}$ during the winter, premonsoon and post-monsoon period, respectively (table 1).

A summary of correlation and RMSE between observed and model simulated seasonal average rainfall in Bangladesh is shown in table 1 in which a better correlation is seen for two seasons than the other seasons. During winter and pre-monsoon seasons, correlation between observed and model rainfall is found to be the same as 0.38 which is statistically significant at $5 \%$ level with RMSE of 170 and $454 \mathrm{~mm}$, respectively while correlation between observed and model rainfall is found to be poor (less than 0.20) with RMSE of 325 and $152 \mathrm{~mm}$, respectively during monsoon and postmonsoon seasons. All these statistical calculations were carried out using software.

\subsubsection{Long term rainfall}

The simulated (GFC) area averaged rainfall over Bangladesh is compared with the CRU gridded $\left(0.5^{\circ} \times 0.5^{\circ}\right)$ rainfall for the period $1961-1990$ and is shown in figure $4(\mathrm{a}, \mathrm{b})$. Spatial distribution of the simulated and the CRU rainfall over Bangladesh are found to be almost similar pattern except in the northeastern part of Bangladesh. Model does not capture rainfall well over northeastern part. But, southeastern and some areas of western parts rainfall is captured well by the model. Southeastern part is located in hilly region and western part is located in large landmass area over Bangladesh and India.

Spatial distribution of differences (CRU Model) in rainfall for the period of 1961-1990 is represented in figure 4(c). Highest rainfall is seen in the northwestern part and next, in some areas of the western part while less rainfall is found to be

Table 1. Characteristics of observed and RegCM simulated (GFC) seasonal and annual rainfall ( $\mathrm{mm}$ ) over Bangladesh during the period 1961-1990.

\begin{tabular}{lrrrrr}
\hline Mean & MAM & JJAS & ON & DJF & Annual \\
\hline Observed & 418.9 & 1729.0 & 211.8 & 33.7 & 2393.4 \\
Baseline (model) & 822.7 & 1876.8 & 259.7 & 166.6 & 3125.8 \\
Standard deviations & & & & & \\
Observed & 148.5 & 228.1 & 97.3 & 20.4 & 312.5 \\
Baseline (model) & 218.3 & 222.1 & 126.7 & 115.09 & 373.8 \\
Mean bias & 403.8 & 147.8 & 47.9 & 132.9 & 732.4 \\
Std. dev. bias & 69.8 & 6.0 & 29.4 & 94.69 & 61.3 \\
Correlations & $0.38^{*}$ & 0.14 & 0.16 & $0.38^{*}$ & 0.09 \\
RMSE & 454.2 & 325.4 & 152.2 & 170.7 & 852.5 \\
\hline
\end{tabular}

$*$ : Correlation significant at $95 \%$ level. 

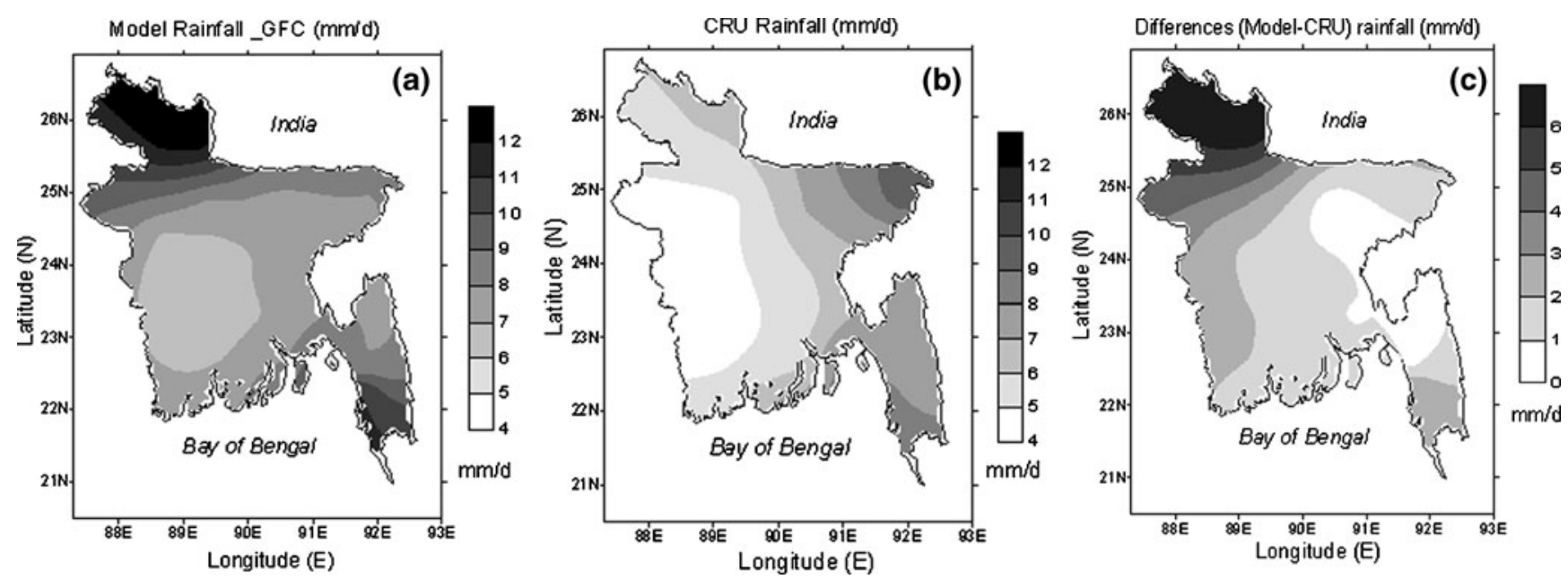

Figure 4. (a-b) Comparison of spatial distribution of model simulated (GFC) rainfall (mm/d) and CRU rainfall during the period 1961-1990. (c) Differences between model and CRU rainfall during the period 1961-1990.

in the northeastern part extending up to southern part of Bangladesh.

\subsection{Simulation of temperature over Bangladesh}

In this section, the simulated (GFC) temperature is compared with the observed data.

\subsubsection{Monthly mean temperature}

The monthly mean annual cycles of the simulated (GFC) temperature are compared with the observed data as shown in figure 5. The

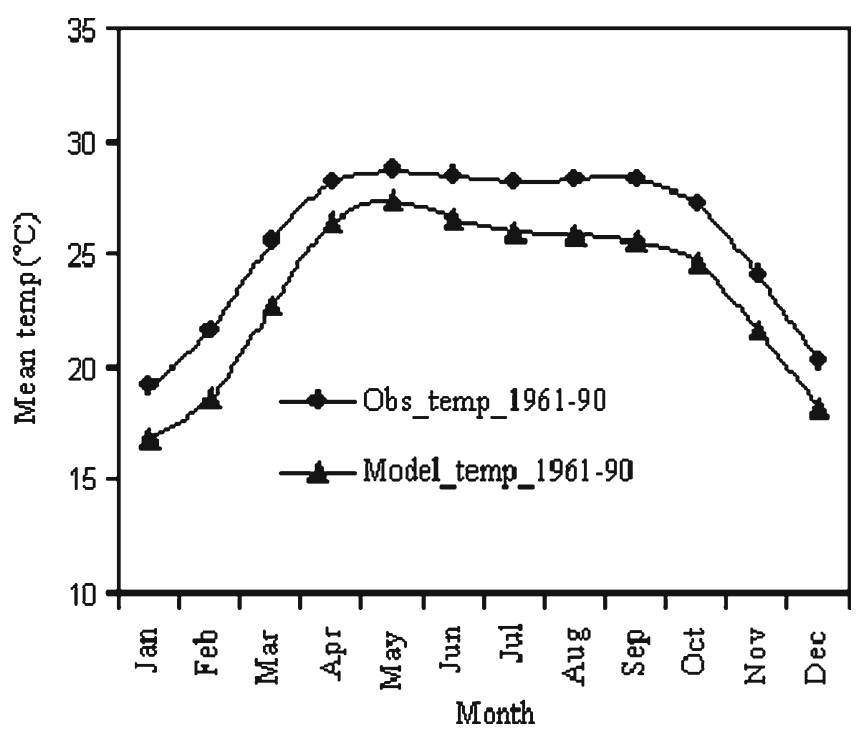

Figure 5. Comparison of simulated (GFC) monthly mean surface air temperature $\left({ }^{\circ} \mathrm{C}\right)$ with the observed data during the period 1961-1990. annual cycles in the surface air temperature having the highest temperature during the pre-monsoon months (April-May) followed by slight temperature decrease during the monsoon months are well represented by RegCM3. These appear to be some cold bias in the model throughout the year. The model-simulated monthly mean surface air temperature are almost the same for all months but magnitude is different from the observed data.

\subsubsection{Seasonal mean temperature}

The model simulated (GFC) average seasonal temperature is compared with the observed data for the four seasons over Bangladesh as shown in table 2. The simulated temperature is seen to underestimate the observation by $2.0^{\circ}, 2.3^{\circ}$, $2.5^{\circ}$ and $2.3^{\circ} \mathrm{C}$ for pre-monsoon, monsoon, postmonsoon, and winter seasons, respectively. The simulated mean pre-monsoon temperature is $25.5^{\circ} \mathrm{C}$ with a standard deviation of $0.4^{\circ} \mathrm{C}$ (table 2). The observed mean pre-monsoon temperature based on 28 stations over Bangladesh is $27.5^{\circ} \mathrm{C}$, with a standard deviation of $0.5^{\circ} \mathrm{C}$. The simulated mean surface air temperature is seen to underestimate the observed value (by $2.0^{\circ} \mathrm{C}$ ) but variability is almost the same for pre-monsoon season. Model shows systematic cold bias for all seasons. However, simulated surface air temperatures are well matched with the pattern as observed over all seasons but magnitude is different. The model simulated surface air temperature underestimates the observation by $2.3^{\circ}, 2.5^{\circ}$ and $2.3^{\circ} \mathrm{C}$ for monsoon, post-monsoon, and winter seasons, respectively. The variation in mean temperature (cold bias for all seasons) may be as seen in the global model. 
Table 2. Characteristics of observed and simulated (GFC) mean temperature $\left({ }^{\circ}\right.$ ) over Bangladesh during the period 1961-1990.

\begin{tabular}{lccccc}
\hline Mean & MAM & JJAS & ON & DJF & Mean temp. \\
\hline Observed & 27.5 & 28.3 & 25.6 & 20.2 & 25.6 \\
Baseline (model) & 25.5 & 26.0 & 23.1 & 17.9 & 23.4 \\
Model bias & -2.0 & -2.3 & -2.5 & -2.3 & -2.2 \\
Standard deviations & & & & 0.4 & 0.2 \\
Observed & 0.5 & 0.2 & 0.5 & 0.7 & 0.4 \\
Baseline (model) & 0.4 & 0.4 & 0.7 & 0.0 & 0.2 \\
Correlations & 0.2 & 0.10 & 0.2 & 2.5 & 2.3 \\
RMSE & 2.1 & 2.4 & 2.6 & & \\
\hline
\end{tabular}

\subsubsection{Long term mean temperature}

Figure 6(a and $\mathrm{b})$ shows the spatial distribution of mean surface air temperature simulated (GFC) by RegCM3 with the CRU data for the period 1961-1990. It is found that the patterns are almost similar but magnitude is different as discussed in earlier section. The CRU temperatures are used for understanding the model performance. This figure shows that the low temperature regions are in the northeastern and northern parts of Bangladesh, whereas high temperature regions are in the southeastern and southwestern parts. Overall, the model shows that a cold bias persists in simulation.

The spatial distribution of differences (CRU Model) between CRU and mean surface air temperature for the period of 1991-1990 are shown in figure 6(c). From the figure, the highest mean surface air temperature is observed in the northeastern and northwestern parts and next to it is found the western part while less mean surface air temperature is found in the southeastern part of Bangladesh.

Figure 7(a and b) shows the spatial distribution of long term mean surface air temperature obtained from (a) model simulation (left side) and (b) observation (right side) for the period of 1961-1990. Simulation shows that low temperature zones are in the northern and eastern parts of Bangladesh. A high temperature zone is observed in the southwestern parts of the country. The spatial distribution of long term observed temperature is obtained from the grid-to-grid method, which is almost similar to the simulated temperature distribution. Therefore, it may be concluded that model data is not directly applicable for any purpose due to model bias and after calibration, model bias may be reduced. Calibrated results may be applicable for various purposes especially in planning for the agriculture, water resources, health, biodiversity, etc., of the country.
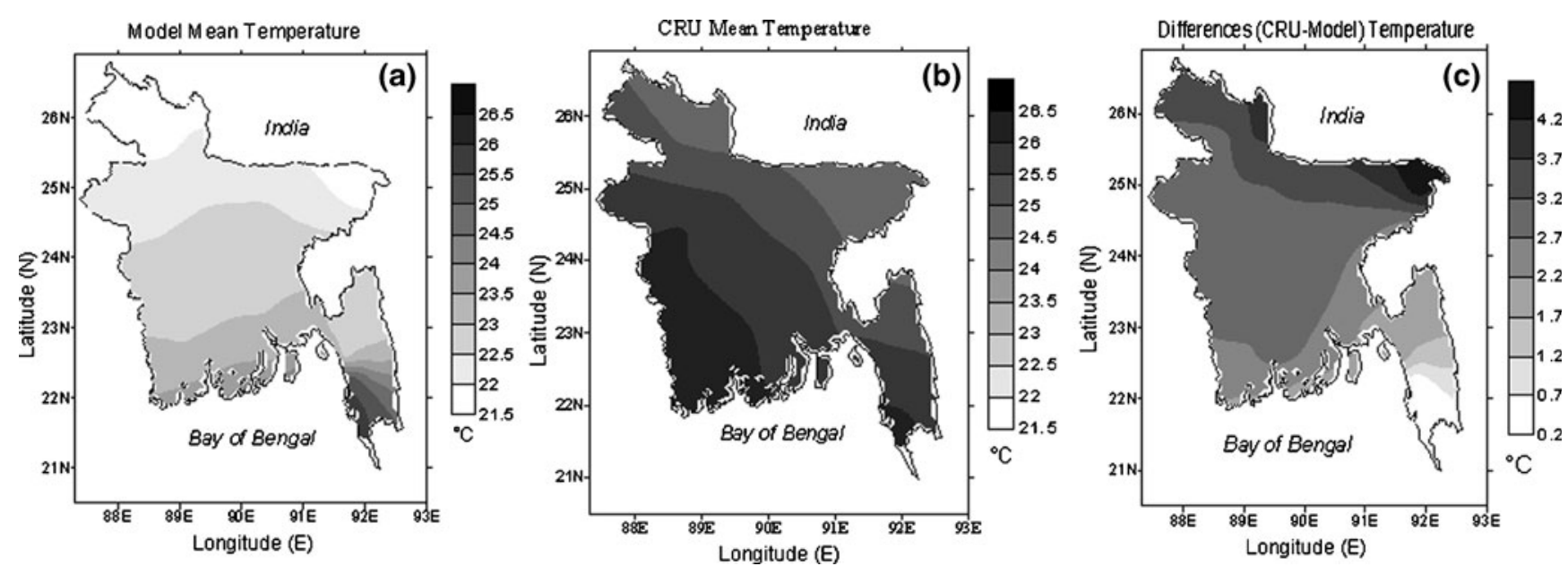

Figure 6. The spatial distribution of (a) model simulated (GFC) mean surface air temperature and (b) the CRU mean surface air temperature during the period 1961-1990. (c) Differences between CRU and model mean temperature during the period $1961-1990$. 

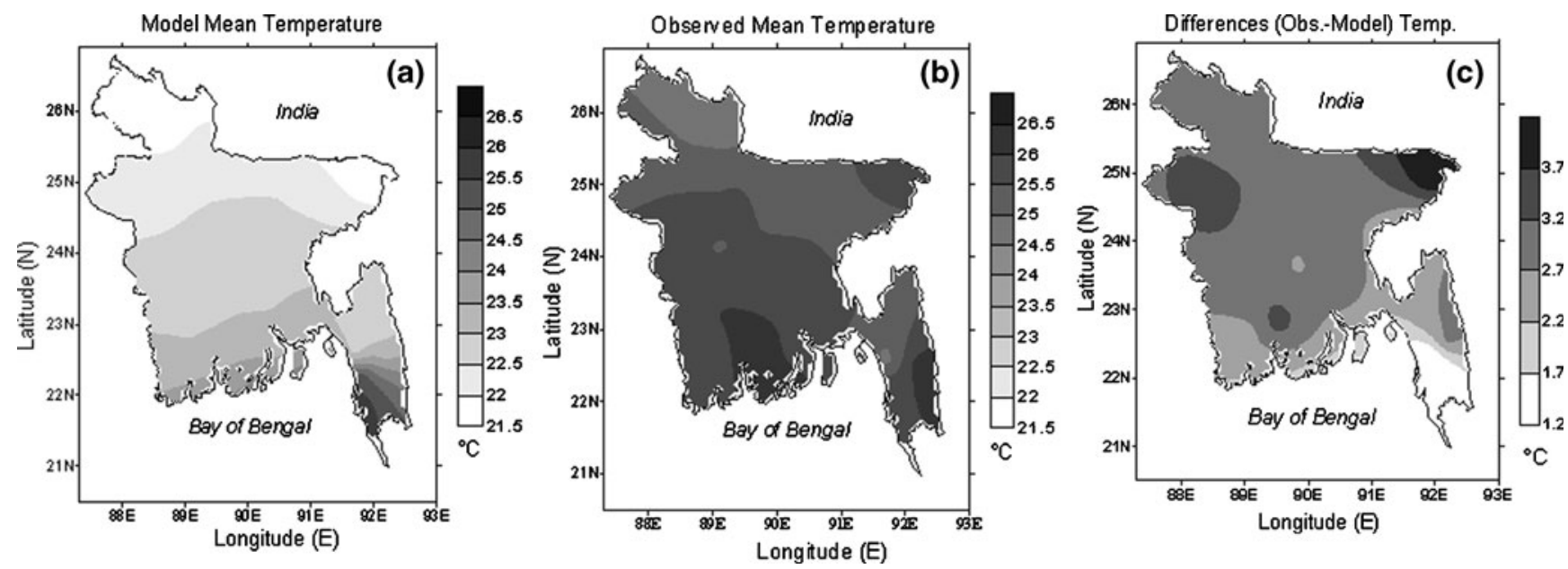

Figure 7. The spatial distribution of (a) model simulated (GFC) mean surface air temperature and (b) observed mean surface air temperature during the period 1961-1990. (c) Differences between observed and model mean temperature during the period 1961-1990.

The spatial distribution of differences between observed and model mean surface air temperature is found over Bangladesh for the period of 1991-1990 are shown in figure 7(c). High mean surface air temperature are seen in some areas of northeastern and western parts while low mean surface air temperature in some areas of southeastern and southwestern parts of Bangladesh. This figure shows almost the similar pattern as in figure 6(c).

\section{Climate change projection}

\subsection{Projection of rainfall}

To reduce model biases in the future precipitation scenario, the observed data and the differences between the future and present data were used to estimate climate scenarios in each season using the following expression:

$$
P_{\text {future }}=P_{\text {obs }}+\left(P_{\text {future }}-P_{\text {present }}\right)
$$

where $P_{\text {obs }}$ is the observed data, $P_{\text {future }}$ is the model future data, and $P_{\text {present }}$ is the model present data.

Rainfall projection is obtained using equation (1) for the year 2050 and 2060. The change of rainfall is found to be $-67 \%,+35 \%,-12 \%$ and $+107 \%$ for pre-monsoon, monsoon, post-monsoon and winter, respectively in 2050 (figure 8) and rainfall on an average may decrease more than $50 \%$ (not shown in seasonal values) in 2060 .

\subsection{Rainfall anomaly in 2050}

Figure 9 shows the spatial distribution of modelsimulated (GFS) rainfall anomaly in 2050 with respect to the average rainfall for the period 19611990. The average rainfall may increase in the eastern part and decrease in the western part of Bangladesh in 2050 with largest negative anomalies in the northwestern region.

\subsection{Projection of temperature}

Temperature projection is obtained using equation (1) as shown in figure 10 for the years 2050 and 2060, respectively. Mean surface air temperature may change in 2050 by $2.1^{\circ}, 1.3^{\circ}, 2.1^{\circ}, 1.6^{\circ}, 1.0^{\circ}$, $0.0^{\circ}, 0.5^{\circ}, 1.1^{\circ}, 1.6^{\circ}, 0.2^{\circ}, 1.9^{\circ}, 1.2^{\circ} \mathrm{C}$ for January, February, March, April, May, June, July, August, September, October, November and December, respectively. Similarly, temperature may change in 2060 by $3.5^{\circ}, 1.7^{\circ}, 3.3^{\circ}, 3.8^{\circ}, 1.2^{\circ}, 2.1^{\circ}, 1.7^{\circ}$, $1.5^{\circ}, 1.9^{\circ}, 1.4^{\circ}$, and $0.9^{\circ} \mathrm{C}$ for January, February, April, May, June, July, August, September, October, November and December, respectively. Mean surface air temperature in various months at different places over Bangladesh may vary by $0.5^{\circ}-$ $2.1^{\circ} \mathrm{C}$ and $0.9^{\circ}-3.5^{\circ} \mathrm{C}$ for the year 2050 and 2060 , respectively.

\subsection{Temperature anomaly in 2050}

Figure 11 shows the differences of model simulated mean temperature of 2050 and the average temperature for the period 1961-1990. It is found that the mean temperature in and around Bangladesh may increase except in some areas of southeastern part of Bangladesh. Model-simulated mean temperature may decrease a little bit in southeastern part of Bangladesh in 2050. The rate of increase of mean temperature in the northern side is higher than that of the southern side of Bangladesh. 


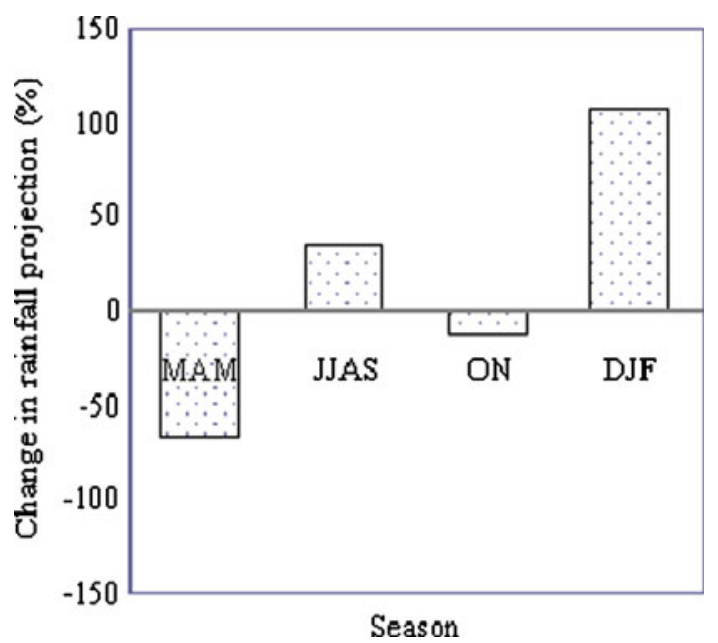

Figure 8. Percentage of change in rainfall projection with respect to baseline for four seasons in 2050 .

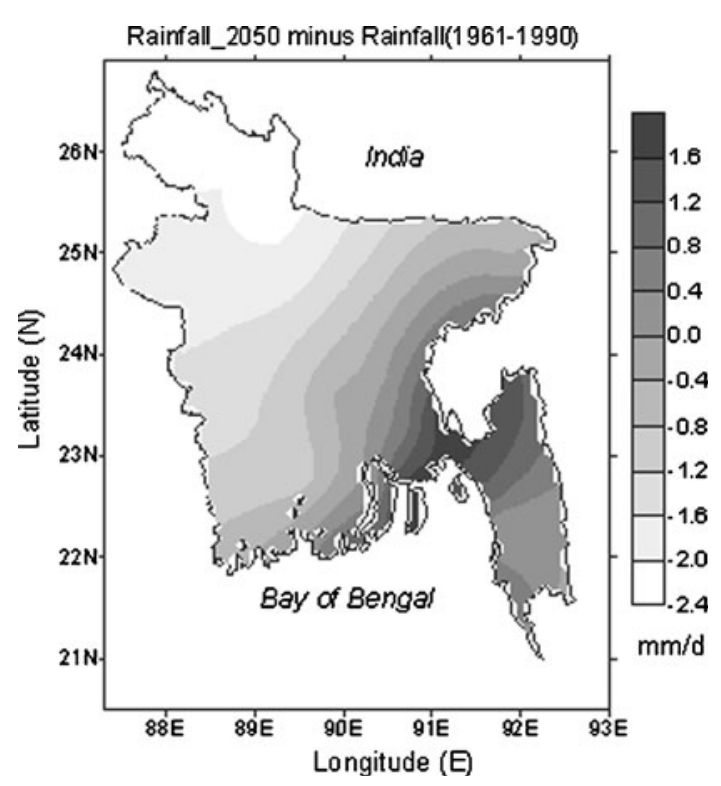

Figure 9. The spatial distribution of rainfall anomaly over Bangladesh in 2050.

\section{Conclusions}

Rainfall and temperature scenarios presented in this paper are very useful for impact assessments in various sectors in Bangladesh. Simulation results are obtained using various options of a regional climate model (RegCM3). Surface air temperature and rainfall show similar patterns of projected changes under A2 scenario over India as found by Rupa Kumar et al (2006). Following are the major conclusions based on the results presented in this paper:

- RegCM3 shows a systematic cold bias for temperature for all months for the period 19611990. On an average, RegCM3 underestimates temperature by $2.3^{\circ} \mathrm{C}$. However, there is a

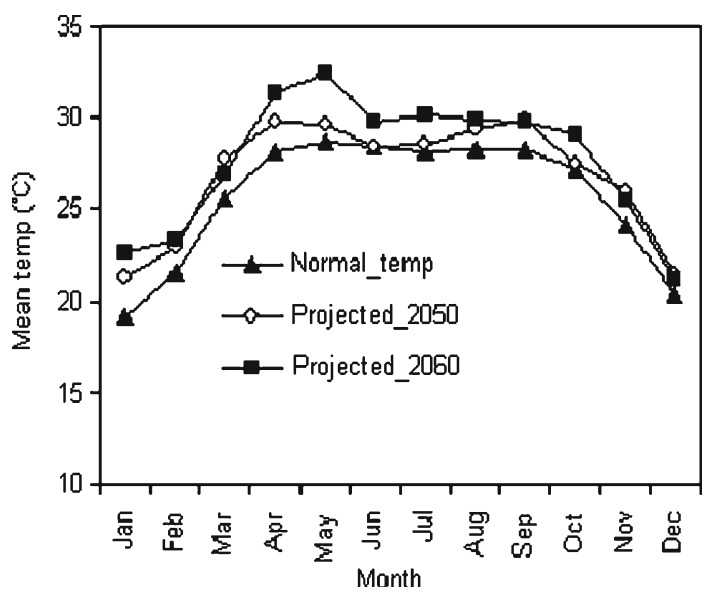

Figure 10. Annual cycle of projected temperature with normal over Bangladesh in 2050 and 2060.

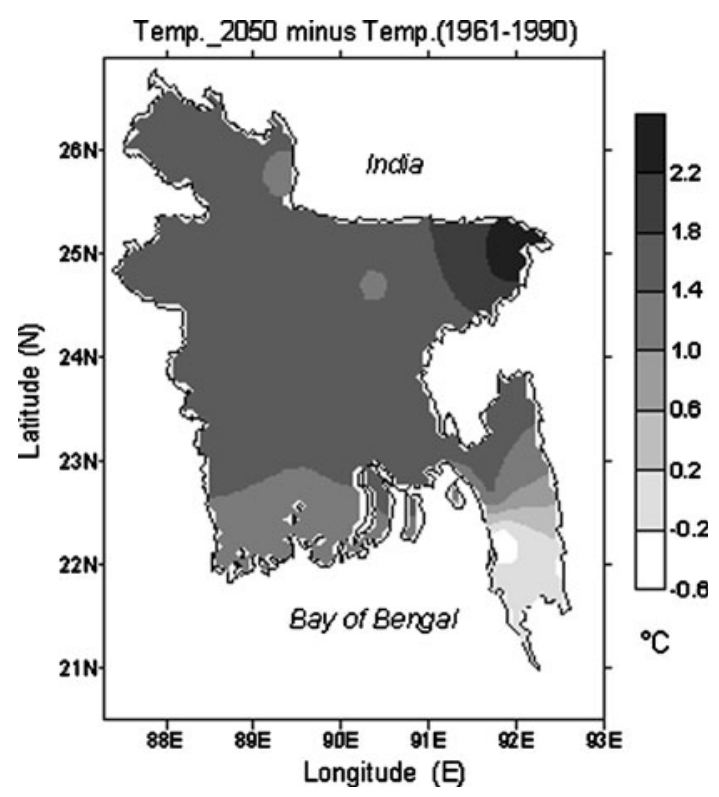

Figure 11. The spatial distribution of mean temperature anomaly over Bangladesh in 2050.

monthwise variability in the model resolved temperature which varies within a range of $1.4^{\circ}-$ $3.0^{\circ} \mathrm{C}$ with respect to observed monthly average temperature.

- A major bias involving overestimation of rainfall over Bangladesh in the regional climate model may be carried down from its parent model (i.e., GCM).

- Model simulated scenarios of increasing greenhouse gas concentrations indicate marked increase in temperature towards the middle of the 21 st century.

- RegCM3 projected temperature indicates that temperature in Bangladesh may increase throughout the country in 2050 and 2060. The rate of increase in temperature may vary from 
$0.5^{\circ}-2.1^{\circ} \mathrm{C}$ and $0.9^{\circ}-3.5^{\circ} \mathrm{C}$ for 2050 and 2060 , respectively.

- RegCM3 projected rainfall indicates that rainfall over Bangladesh may change by $-67 \%,+35 \%$, $-12 \%$ and $+107 \%$ for MAM, JJAS, ON and DJF, respectively in 2050 and rainfall on an average may decrease by more than $50 \%$ in 2060 .

\section{Acknowledgements}

The first author is grateful to ICTP, Italy for providing the opportunity for research work at ICTP and also to the Director, SAARC Meteorological Research Centre (SMRC), for allowing him to work as a Regular Associate at the ICTP to conduct this study. The Bangladesh Meteorological Department (BMD) is acknowledged for providing observational data.

\section{References}

Ali A 1999 Climate change impacts and adaptation assessment in Bangladesh; Climate Res. 12 109-116.

Bengtsson L M, Botzet and Esch M 1996 Will greenhouse gas-induced warming over the next 50 years lead to higher frequency and greater intensity of hurricanes? Telllus 48A $57-73$.

Dickinson R E, Errico R M, Giorgi F and Bates G T 1989 A regional climate model for the western United States; Climatic Change 15 383-422.

Fritsch J M and Chappell C F 1980 Numerical prediction of convectively driven mesoscale pressure systems. Part 1: Convective parameterization; J. Atmos. Sci. 37(8) 1722-1733.

Giorgi F, Hewitson B, Christensen J H, Hulme M, VonStorch H, Whetton P, Jones R, Mearns L O and Fu C 2001 Regional climate information - Evaluation and projections; In: Climate Change 2001 (eds) Houghton J T, Ding Y, Griggs D J, Noguer M, Van der Linden P J and Xiaoxu D (Cambridge, UK: Cambridge University Press), pp. $583-638$.

Grell G A, Dudhia J and Stauffer D R 1994 A description of the fifth-generation penn state/ncar mesoscale model (mm5), Technical report, National Centre for Atmospheric Research.

Giorgi F 1990 Simulation of regional climate using a limited area model nested in a general circulation model; J. Climate 3 941-963.
Houghton J T, Ding Y, Griggs D J, Noguer M, van der Linden P J, Dai X, Maskell K and Johnson C A (eds) 2001 Climate Change 2001: The Scientific Basis, Contribution of Working Group 1 to the Third Assessment Report of the Intergovernmental Panel on Climate Change, Cambridge University Press, 892p.

Haq S, Karim Z, Asaduzzaman M and Mahtab F (eds) 1998 Vulnerability and Adaptation to Climate Change for Bangladesh (Dordrecht: Kluwer Academic Publishers), $135 \mathrm{p}$.

Houghton J T, Meira Filho L G, Callander B A, Harris N, Kattenberg A and Maskell K (eds) 1995 Climate Change 1995: Intergovernmental Panel on Climate Change (IPCC), Cambridge University Press, Cambridge.

Islam Nazrul M, Rafiuddin M, Ahmed A U and Kolli R K 2008 Calibration of PRECIS in employing future scenarios in Bangladesh; Int. J. Climatol. 8 617-28, doi: 10.1002/joc. 1559 .

Islam Nazrul M and Uyeda H 2008 Vertical variations of rain intensity in different rainy periods in and around Bangladesh derived from TRMM observations; Int. J. Climatol. 28 273-279, doi: 10.1002/joc.1585.

IPCC 2001 Climate Change 2001: The scientific basis. Contribution of Working Group I to the Third Assessment Report of the Intergovernmental Panel on Climate Change (eds) Houghton J T Y, Ding D J, Griggs M, Noguer vander P J, Linden X Dai, Maskell K and Johnson C A (Cambridge, United Kingdom and New York, USA: Cambridge University Press).

IPCC 1996: Technical Summary. In: Climate Change 1995: Impacts, Adaptations and Mitigation of Climate Change: Scientific-Technical Analyses, Contribution of Working Group II to the second assessment report of the Intergovernmental Panel on Climate Change, (eds) Watson $\mathrm{R}$ T, Zinyowera M C and Moss R H (Cambridge: Cambridge University Press), pp. 1-53.

Jones R G, Noguer M, Hassell D C, Hudson D, Wilson S S, Jenkins G J and Mitchell J F B 2004 Generating high resolution climate change scenarios using PRECIS, Met Office Hadley Centre: Exeter.

Karim Z, Hussain Sk G and Ahmed A U 1998 Climate Change Vulnerability of Crop Agriculture, Kluwer Academic Publishers, Dordrecht, 35.

Rahman M M, Islam M N, Ahmed A U and Afroz R 2007 Comparison of RegCM3 simulated meteorological parameters in Bangladesh: Part I - preliminary result for rainfall; Sri Lankan J. Phys. 8 1-9.

Rupa Kumar K, Sahai A K, Krishna Kumar K, Patwardhan S K, Mishra P K, Revadekar J V, Kamala K and Pant G B 2006 High-resolution climate change scenarios for India for the 21st century; Curr. Sci. 90(3) $334-345$. 